\title{
POLITICAL PARTICIPATION IN LOCAL GOVERNMENT PLANNING PROCESSES AS CHANGE AGENT IN REDUCING INEQUALITY TO INCREASE ECONOMIC GROWTH
}

\author{
Kristina L. Wright
}

Departament of Political Science, University of Florida, United States. klwright@ufl.edu

\begin{abstract}
Inequality can be reduced through greater political participation, and reduced inequality often results in increased economic growth (Solt, 2008). This research begins with the examination of the City of Miami, Florida and the City of Denver, Colorado as case studies as part of a Qualitative and Mixed Methods Research Design to consider how inclusion, economic growth, and inequality are affected by these processes. The aim is to consider the quality of participatory methods and analyses while exploring the need for ongoing participation. Externalities such as changing property values are considered as a factor in evaluating inequality to more holistically analyze processes and outcomes. The research objectives include measuring and analyzing how a multi-faceted research design with the use of visual communication within public planning processes can further economic growth, while advancing inclusion and levels of collaboration within local government public planning participation processes in the United States. To maximize the impact of this study and to uncover reflexive benefits, the need for further research of local contexts internationally has been uncovered. This will serve as a test in achieving maximum, true diversity and the highest and best returns in terms of economic growth through the reduction of inequality. As such, this study acknowledges the need to continue to replicate this research domestically and internationally for comparative purposes to ensure the opportunity for maximum collaboration and the most thorough investigation and findings into the achievement of economic growth through the reduction of inequality.
\end{abstract}

Keywords: Political Participation, Economic Growth, Inequality, Case Studies, Mixed Methods.

\section{INTRODUCTION}

Within local government, planning offers rare opportunities, and perhaps the only opportunity, for citizens to influence public policy and directly participate in governmental policy- and decision-making processes. As such, planning presents a critical opportunity in decentralized forms of governance to provide public political participation and scholars like Frederick Solt (2008) have asserted that political participation can reduce inequality. As such, this study is centered on exploring these factors through an analysis of the following question: How does political participation increase economic growth and how does political participation reduce inequality? Local government planning processes can present quality and meaningful public participation opportunities. Often the creation of Form-based Codes presents highly participatory and visual processes that are highly attended by the public. While economic returns following the implementation of Form-based Codes are often robust, in what manner is inequality reduced and what is the relationship between participation, economic growth, and inequality? Case studies are selected and analyzed to uncover how inequality is directly affected by public political participation as well as considering the 
potential for endogenous and exogenous outcomes that may perpetuate inequality that may surface in decreased levels of housing affordability alongside robust levels of economic growth while reducing participatory inequality.

\section{SIGNIFICANCE}

The significance of this study is to identify the benefits of advanced participation opportunities to maintain economic growth and maximize the reduction of inequality to improve the economic health of our communities, advance the quality of life, and to demonstrate the intrinsic value of political participation opportunities and the value of local government planning to provide at least one source for quality, direct, and meaningful public political participation to directly shape policy that combats inequality while bolstering economic growth. Through this study, innovations in political participation are considered for the ability to increase levels of predictability and economic return in relation to the reduction of inequality. The robust growth that often accompanies public planning and visioning processes may create a scenario where resulting inequality that can occur exogenously to these processes is being overlooked. This study also considers whether there is a need to further attempt to reduce inequality by increasing the opportunity for ongoing political participation.

High rents and high housing costs may not only effect income inequality, but it is also a possibility that someone with high rent or high mortgage costs may have difficulty making participation a priority. If front-loaded political participation increases predictability while reducing opportunities for ongoing participation, an increase in inequality will likely occur and therefore will decrease the opportunity to reduce inequality. If robust economic growth leads to gentrification are tools such as commercial linkage fees necessary to provide housing within the $30 \%$ of household income threshold?

Political participation reduces inequality in terms of process; however, exogenously homeownership rates have been declining and the percentage of households that are cost burdened are increasing (Solt, 2008; Florida Housing Finance Corporation, 2016). Is this inequality a result of the robust economic growth that results from front-loaded participatory processes? Do these participatory processes and the resulting economic growth also result in significant actual value increases which lead to greater housing rents and costs? 
Next, there is the belief that for political participation to effectively combat inequality, it must be meaningful. Prior research (Wright Bowen, 2011) found that each code formulation process within each case was considered meaningful after being subjected to process and outcome criteria for meaningful participation established by Innes and Booher (1999). Political participation opportunities in local government planning are often useful in advancing economic growth and can reduce participatory inequality. In sum, even advanced political participation processes may generate outcomes that could necessitate remedies to mitigate exogenous inequitable outcomes.

\section{BACKGROUND}

This study began as an exploration into the processes and outcomes that accompany the creation and implementation of different code types. These code formulation processes are necessary within planning implementation as regulations need to be responsive and achieve the goals that a community envisions. After observing the strong economic impact that often accompanies form-based codes, the study advanced to consider economic growth and for whom. The process seems to secure the financial future of property owners while marginalizing those dependent on rents to secure housing. The study then began to examine the property values before and after the code formulation processes involved in both the City of Miami, Florida and Denver, Colorado. The results produced similar outcomes, which followed code implementation and adoption where property values in both contexts significantly increased following these well-attended participatory processes.

There are several methods and frameworks for analyzing and measuring inequality; however, this study examines political participation within planning processes where inequality is evaluated in terms of the quality, extent, timing, and access to participation and the ability to influence and shape processes and outcomes. Additionally, inequality is considered not only in terms of the accessibility and quality of participation opportunities, but also in terms of affordable levels of homeownership that comprises $30 \%$ of a household's budget, which is the threshold established by the U.S. Department of Housing and Urban Development as well as the U.S. Census Bureau. This analysis also considers exogenous effects of processes that produce robust economic growth for property owners and local governments collecting tax revenues yet may inadvertently marginalize populations not in a position situated to gain from the benefits of advanced planning. Quality, collaborative planning processes can improve the quality of life through a reduction in inequality and the 
achievement of a vision that is responsive and authentic to the values and desires of the community (Solt, 2008).

The objective of this study is to consider how to advance public political collaboration to mitigate the potential for any negative externalities in order to produce greatest outcomes, which can include increased economic returns and livability while also considering the role of housing as an opportunity and as an indicator of equality and the potential for economic growth at the local government and individual property owner level. These analyses are setting the stage for local international comparative analyses to advance innovation and to measure and analyze levels of economic growth and the most diverse methods of inclusion.

Another objective of this study is to examine the difference in function and implementation of regulatory formats through project analyses, which test the need for on-going participation within planning processes. The importance of this study is based on current research of Frederick Solt (2008), which has shown that meaningful participation reduces inequality. Land Value analyses that involve the consideration of hypothetical site plans will be subjected to each regulatory format to determine the effect of each code type on producing certainty while considering the need for additional participation. These analyses consider another facet of the work of Frederick Solt, which evaluates the need for different definitions of inequality to most effectively consider the ability to reduce overall inequality (2008). For the purpose of this study, meaningfulness is defined as the ability to shape public policy. According to Fung (2004), participants need to be decision-makers producing visible outcomes for participation to be considered meaningful and empowered.

Form-based codes appear to increase the levels of economic growth in the community as a result of highly prescriptive regulations that present a great opportunity for community buy-in at the beginning of the process. In both contexts, housing values increased even following the economic downturn when each form-based code was adopted. Data obtained from the Florida Housing Finance Corporation (2016) also demonstrates the significant increases in the cost of renting following the period that corresponds to form-based code adoption and implementation. While participation increased dramatically within both case study contexts, it can be assumed that inequality was decreased in terms of increased opportunities to participate. However, in terms of reduction in inequality of individual homeownership rates, the data indicates that there has been a decline in the levels of homeownership in both contexts while property values and the cost to rent has increased (Florida Housing Finance 
Corporation, 2016 and U.S. Census data, 2018). For homeowners there were gains due to increased property values; however, for renters the cost to rent continued to increase as the inventory of available rentals began to decrease (Florida Housing Finance Corporation, 2016).

Throughout this study, local government planning participatory processes have been considered for their role to provide a unique opportunity for the public to meaningfully participate and engage a decision-making process that can shape public policy. Regulatory frameworks have been considered for externalities of increasing economic growth and for the potential to decrease inequality. If highly prescriptive code types increase participation at the beginning stages of the code formulation process but leave few opportunities for participation later while property values continue to outpace the supply, are policies that produce tools such as linkage fees necessary to offset these externalities? These are tools that can ensure an adequate supply of workforce and affordable housing to eliminate further burden on public infrastructure and resources while increasing the overall quality of life.

Highly attended processes of form-based code formulation can lead to increased property values, which can create economic growth for the local government and the homeowner; however, the participatory renter likely only experienced a decrease in inequality in terms of participation if all other factors remain constant while the supply of affordable rental units have decreased (Florida Housing Finance Corporation, 2016).

According to Thomas (2017) there is value in the ability to become "authors" within political participation processes, which allow participants to shape their own destiny; however, if selfdetermination is limited to participation, economic mobility and the reduction of financial inequality is limited once the conversation ends and the policies are in place. Linkage fees and policies are necessary to ensure an adequate supply of workforce and affordable housing is available if form-based codes produce economic growth only for the local governing body, land-, and homeowners.

\section{EXISTING LITERATURE}

To explore the relationship between political participation and inequality, Frederick Solt (2008) asserts that inequality has been increasing over the past two decades. Political participation research is needed to better define, understand, and even attempt to mitigate political inequality through participation since there is limited research in this area. Local 
government planning participatory processes may present rare opportunities for many to experience direct political participation. A study of local governments in 2001 found a positive relationship between inequality and local government political participation (Solt, 2008). According to Solt (2008), research also has shown that greater inequality corresponds to lower levels of political participation and inequality also leads to a decline in the opportunity to meaningfully participate and influence public policy. Both processes and outcomes present opportunities to eliminate inequality.

When participants become co-collaborators or "self-authors" they gain control over their wellbeing through "social connectedness" that stems from these political participation processes (Thomas, 2017, p. 867). Individual contributions towards collaborative, collective efforts are critical at a time when elitism in democratic politics has resulted in the disenfranchisement of citizens from the processes and systems that were designed to represent and incorporate all interests (Thomas, 2017). Furthermore, the local government benefits from the public participation that results in locally specific, unique, and distinctive places that more robustly attract economic development due to context specificity (Rangwala, 2010).

\section{EMPOWERED PARTICIPATION}

Social change is also affected by strong political participation and, according to Fung (2004), empowered participation occurs when participants can actively participate and make decisions that produce results with visible outcomes. This calls for the consideration of the role of political participation in marketing and building initiatives that will develop unique places representing vested public ownership due to the development of strong emotional attachments and a sense of place that further advances economic growth (Rangwala, 2010). The political participation process in form-based code formulation processes are centered on the visual nature and design-orientation of form-based codes. Collaboration and process outcomes are based on visual communication that provides a more universal and sensory language that maximizes inclusivity as it presents an opportunity to engage the participant at a more dynamic, complex, and profound level than conventional zoning codes. Conventional zoning codes are based on legal text often with limited or even no visual imagery that produces a more abstract and ambiguous set of restrictions rather than visually clarifying the vision, expectations, and possibilities. Form-based code formulation processes lead to visible collaboratively derived outcomes, which more closely align with the notion of empowered and meaningful participation. Why has so little research been done to analyze participatory 
outcomes of political participation processes? According to Jun (2017), there is a lack of methods for analyzing outcomes. As such, this study considers the need for further exploration of outcomes that accompany political participation opportunities to form a more profound investigation through the examination of the source and methods and measures needed to reduce inequality.

Based on Solt's 2008 work, it is asserted that participation reduces inequality, but how will this be realized? Through an examination of local government planning code formulation participatory processes, we can begin to consider the outcome of economic returns following code implementation; however, we need to factor in different definitions of inequality. Inequality in terms of participation is much different than inequality in terms of outcome or individual economic realities. Next, we will see how case studies and housing and land value analyses are examined to uncover how inequality is combated trough process and to begin to consider the need to factor in how inequality is affected as endogenous and exogenous outcomes, such as housing affordability that may perpetuate inequality.

\section{METHODOLOGY}

We used case studies and before-and-after analyses that consider the effects of each regulatory type as applied to each development scenario and the opportunity and need for further participation. We also used before-and-after analyses of housing costs, homeownership levels, and a qualitative analysis of meaningful participation criteria established by Innes and Booher (1999) that is an important foundational evaluative method established in prior research (Wright Bowen, 2011).

\section{RESEARCH DESIGN}

Case studies are used to explore the extent, timing, format, and quality of political participation processes and outcomes in different, yet comparable contexts. Both Miami, Florida and Denver, Colorado (US) are major metropolitan areas that entered the form-based code formulation processes at nearly the same time, and both involved a high level of public political participation. The visual nature of these codes allows a common language to engage a diverse audience on a level of greater complexity than text and abstract concepts and regulations. Visual communication employed within case studies "offer new opportunities to distinct and sometimes marginalized groups, which broadens... wider understanding" (Watt \& Wakefield, 2017, p. 195). Both case study contexts featured the creation of codes that were 
highly visual in nature and both code formulation processes were highly attended. In turn, these processes advance economic growth within communities through processes that strengthen the local economy due to the development of strong emotional bonds and a sense of place for the participants (Rangwala, 2010). The renderings of the interactivity of public and private spaces and places encourages a dialogue that would be difficult to describe alone on a verbal level. Visual methods engage participants with "deeper meaning and empathy both as individuals and when working with others" (Watt \& Wakefield, 2017, p. 196). After factoring levels of participation during code formulation, the results were examined to uncover the likelihood of and the need for latent participation following the adoption of the code to continue the dialogue with the public to continue to increase economic growth by reducing inequality.

Miami and Denver's code formulation processes were built on extensive political participation opportunities, involving hundreds of public meetings that exhibited the achievement of process and outcome criteria that were deemed meaningful based on criteria established by Innes and Booher (1999). The Process Criteria and the Outcome Criteria within Figure 1 and Figure 2 set the stage for case characterization that enables advanced analysis that is critical to this study since it is meaningful participation that reduces inequality (Solt, 2008).

\begin{tabular}{|c|c|c|}
\hline $\begin{array}{l}\text { Process Criteria } \\
\text { (Source: Innes and Booher, 1999) }\end{array}$ & Miami & Denver \\
\hline $\begin{array}{l}\text { Included representatives of all relevant and significantly different } \\
\text { interests }\end{array}$ & $Y$ & $Y$ \\
\hline $\begin{array}{l}\text { Was driven by a purpose and task that are real, practical, and } \\
\text { shared by the group }\end{array}$ & $Y$ & $Y$ \\
\hline $\begin{array}{l}\text { Was self-organizing, allowing participants to decide on ground } \\
\text { rules, objectives, tasks, working groups, and discussion topics }\end{array}$ & $Y$ & $Y$ \\
\hline $\begin{array}{l}\text { Engaged participants, keeping them at the table, interested, and } \\
\text { learning through in-depth discussion, drama, humor, and } \\
\text { informal interaction }\end{array}$ & $Y$ & $Y$ \\
\hline $\begin{array}{l}\text { Encouraged challenges to the status quo and fostered creative } \\
\text { thinking }\end{array}$ & $Y$ & $Y$ \\
\hline $\begin{array}{l}\text { Incorporated high-quality information of many types and } \\
\text { assures agreement on its meaning }\end{array}$ & $Y$ & $Y$ \\
\hline $\begin{array}{l}\text { Sought consensus only after discussion have fully explored the } \\
\text { issues and interests and significant effort has been made to find } \\
\text { creative responses to difference }\end{array}$ & $\mathrm{Y}$ & $Y$ \\
\hline
\end{tabular}

Figure 1. Process Criteria Analysis. Source: Innes and Booher (1999, p. 419).

This exploration has evolved from political participation involved in code formulation to an examination of political participation as a catalyst to reduce inequality while increasing economic growth as a process and as an outcome externality based on differences that arise from regulatory framework selection and context. Opportunities for on-going political participation are also considered. 


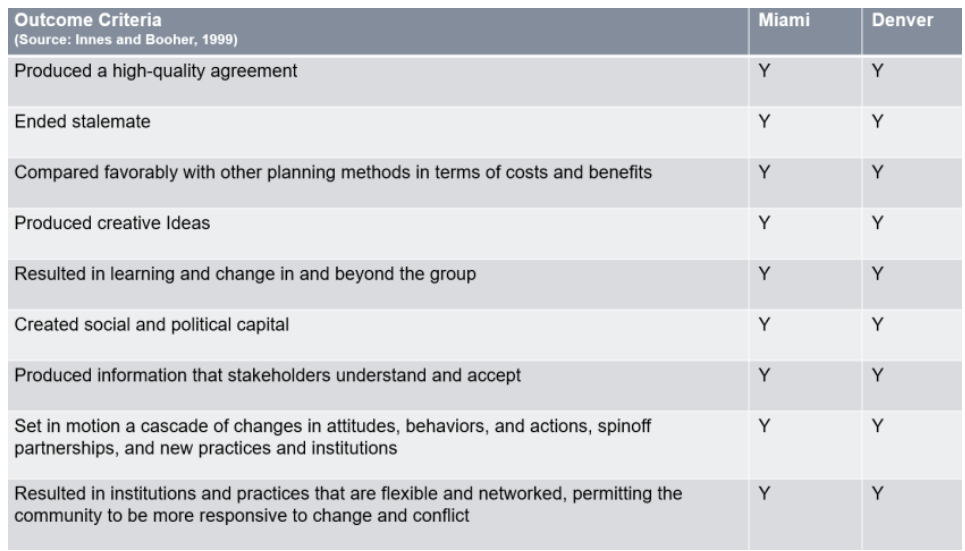

Figure 2. Outcome Criteria Analysis. Source: Innes and Booher (1999, p. 419).

Market and assessed values are examined to consider the exogenous effects of political participation processes of regulatory frameworks based on extensive, front-loaded participation between different contexts to see if the changes are likely to be context specific or if there is some consistency between cases to begin to consider the likelihood of further correlations. In addition to participatory equality, equality in terms of home ownership and cost burdened were examined by analyzing the data from five (5) year periods since the adoption of the form-based code and five (5) years prior to the implementation of the formbased code.

\subsection{Cases: Miami, Florida and Denver, Colorado}

The creation of Miami's form-based code, Miami 21, involved approximately 5 years and a cost of $\$ 3$ Million. This code created by Duany Plater-Zyberk features a strong design orientation and the use of visual communication, which represents a dramatic departure from conventional zoning code types. This new code was developed to overcome the shortcomings of the prior conventional zoning code, Ordinance 11000. These political participation opportunities were highly attended and involved more than 200 public meetings. Miami 21 is a visual, streamlined, design code in which predictability has been generated through specific context-based approaches that serve to masterplan the city. While there is a tremendous increase in the level of predictability due to extensive community buy-in, there are limited participation opportunities following code adoption and implementation.

The Denver form-based code formulation process also took about 5 years, but cost considerably less, coming in at $\$ 850,000$. Like Miami, Denver also sought to overcome the shortcomings of the previous conventional zoning code, Chapter 59 (City of Denver, 2010). 
This political participation process was also a highly attended, meaningful code formulation process, featuring a context-based and form-based approach incorporating a strong designorientation that advanced participation through visual communication. The result of this process has produced user-friendly, specific regulations that also increase predictability.

\section{ANALYSES}

The following analyses feature single author analyses where the control was created using the same property replicated through various time periods reflective of before-and-after analyses of the form-based code formulation processes. These analyses were performed for both case study contexts across the same time intervals. Property value analyses are taken from the parcels depicted in Figure 3 and Figure 5 are used to begin to consider the source of declining homeownership rates and income analyses are also used to consider the root of the increase in cost burdened households. Housing data obtained from the U.S. Census Bureau (2018) and the Florida Housing Finance Corporation (2016) and property tax information obtained from both respective counties, Miami-Dade County and Denver County, are used to capture the values prior to code formulation and following code formulation. Data analysis used establishes a conversation through a then and now snapshot of housing values to consider housing affordability and economic growth while factoring in the potential for outcome inequality.

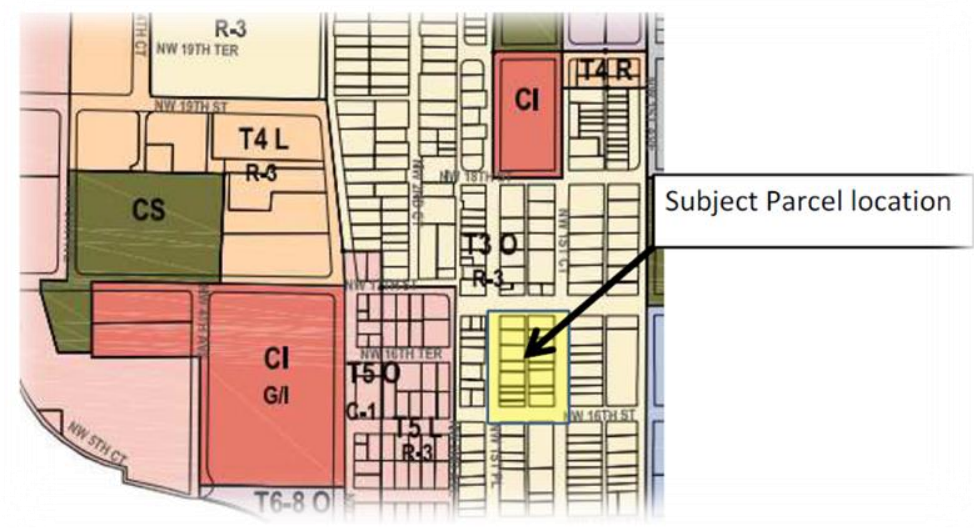

Figure 3. Miami Subject Parcel Location. Source: City of Miami, 2019.

Miami Dade County adjusted rapid increases by providing homestead exemptions that keep escalating property values at bay in terms of taxation. However, the individual seeking to purchase a home is subject to a market with greater volatility and the potential for greater 
levels of taxation due to increased actual, market, and appraised values that result from a latent entry into the market relative to other factors being relatively constant within a proximate reference of time. By utilizing the same property in each analysis at different intervals in time, we can begin to consider how changes occurring may affect affordability levels before and after extensive participation opportunities. While the examination of existing research has indicated that advanced participation can reduce inequality (Solt, 2008), there is a need to consider how inequality may be produced in other areas perhaps requiring advanced conversations on housing affordability within code formulation processes to best support market dynamics. In Denver County, the actual value is subject to a formula that produces a very low assessed value from which to calculate property taxes that has a similar effect and intent as the homestead exemptions used throughout the State of Florida.

\begin{tabular}{|l|l|l|l|}
\hline Miami & $\mathbf{2 0 1 0}$ & $\mathbf{2 0 1 5}$ & $\mathbf{2 0 1 7}$ \\
\hline 1541 NW 1 PL & 180,429 & 220,000 & 235,000 \\
& & $+39,571$ & +54571 \\
\hline 1535 NW 1 PL & 220,029 & 220,000 & 235,000 \\
& & & +14971 \\
\hline 1525 NW 1 PL & 529,828 & 600,000 & 700,000 \\
& & $+70,172$ & $+170,172$ \\
\hline 161 NW 15 ST & 251,374 & 247,500 & 299,475 \\
& & & $+48,101$ \\
\hline 1540 NW 1 CT & 552,000 & 528,000 & 638,880 \\
& & & $+86,880$ \\
\hline
\end{tabular}

Figure 4. Miami Land Value Analyses. Source: Miami-Dade County Property Appraiser, 2019.

The findings demonstrated within Figure 4 and Figure 6 demonstrate that prior to 2010 most housing property taxes remained relatively stable from year to year primarily in both Denver and Miami. However, since 2012 and on-going, values have been rapidly increasing overall in both contexts. In Florida, according to the Florida Housing Finance Corporation's (FHFC) 2016 Rental Market Study, homeownership rates fell 6\% (from 71\%-65\%) from 2007 until 2014. Miami's homeownership rates specifically also continue to fall. In 2000 the home ownership rate was 35\%, and in 2010 it fell 3\% to $32 \%$ and in 2016 it was 31\% according to FHFC (2016). Colorado's homeownership rate $70.2 \%$ in 2007 and fell to $62.4 \%$ in 2016 according to the U.S. Census Bureau (2018). Meanwhile, according to the U.S. Census Bureau, the median household income in Miami was just \$44,224 in 2016. 


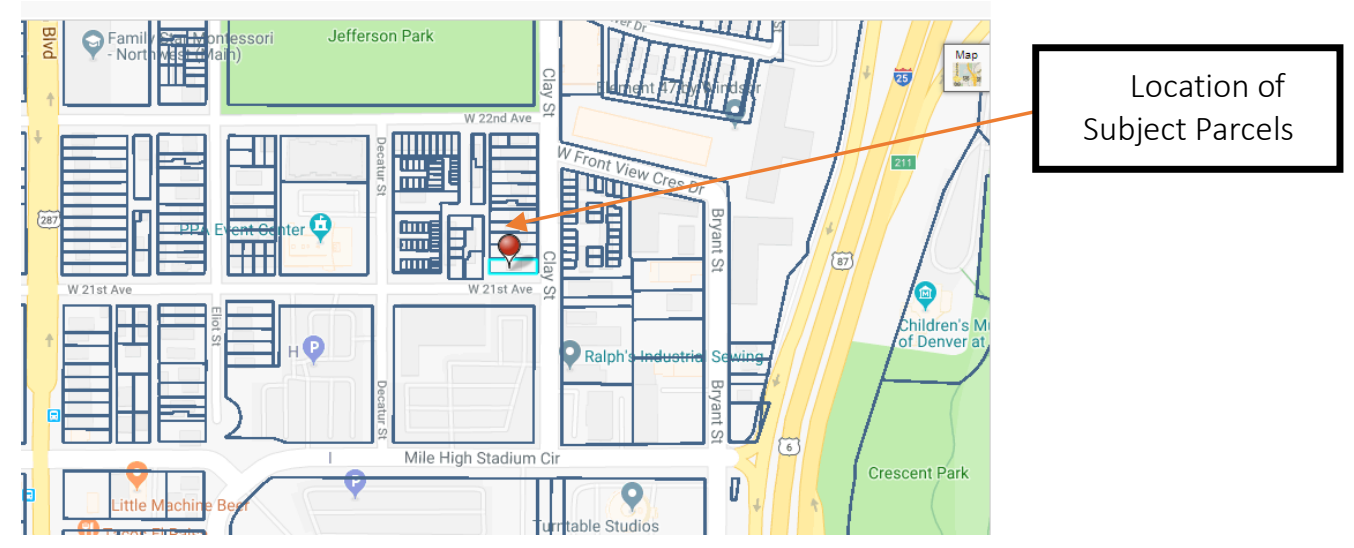

Figure 5. Denver Subject Parcel Location. Source: Denver County Property Appraiser, 2019.

Growth U.S. Census data reveals the growth that Denver is also experiencing (2018). In 2010 , the total number of household units was 286,635 and the population was 604,879 people. In 2016, the total number of household units was 314,631 and the population was 693,292 people. Total number of households in 2010 was 265,233 and in 2017 there were 311,384 households and in 2025 it is projected that there will be 367,086 households in Denver. Single family or multifamily units were selected in similar contexts within each case study for comparison purposes. Each property in each context has seen increases overall since 2010. Meanwhile the median household income in Denver was just $\$ 56,258$ according to the U.S. Census Bureau.

\begin{tabular}{|l|l|l|l|}
\hline Denver & $\mathbf{2 0 0 9}$ & $\mathbf{2 0 1 0}$ & $\mathbf{2 0 1 7}$ \\
\hline $\mathbf{2 1 0 1}$ Clay & 316,000 & 316,000 & $\begin{array}{l}633,300 \\
+317,300\end{array}$ \\
\hline 2107 Clay & 147,700 & 147,000 & 325,700 \\
& & & $+178,000$ \\
\hline 2109 Clay & 222,200 & 222,200 & 454,600 \\
& & & $+232,300$ \\
\hline 2117 Clay & 160,800 & 160,800 & 292,600 \\
& & & $+131,800$ \\
\hline 2123 Clay & 350,500 & 350,00 & 621,800 \\
& & & $+271,300$ \\
\hline
\end{tabular}

Figure 6. Denver Land Value Analyses. Source: Denver County Property Appraiser website, 2019. 


\section{DISCUSSION}

Through the exploration of political participation as an agent of change that can reduce inequality, we find a non-traditional measure of economic growth where the reduction of inequality through public political participation is another form of economic development. By analyzing public political participation processes and considering the notion of inequality more holistically we find avenues to further explore critical, reflexive relationships to more completely understand the power of public political participation and its relationship in improving inequality in the quest to advance the quality of life through complex, yet meaningful, interdisciplinary conversations.

These qualitative analyses depicting the level, quality, and extent of participation alongside property value analyses have demonstrated how political participation can affect inequality in terms of reducing participatory inequality and show that other measures of inequality may be affected by processes that bolster economic growth.

Findings of this study include that both form-based code participatory processes within each context produced high levels of participation, and both were highly visual-based. Both Miami and Denver produced extensive participation for the development of the form-based codes for each city. While these public participation workshops were highly attended, ongoing opportunities to continue to participate are limited, and in some cases non-existent, following code adoption within each context. While there are increasing levels of new technologies including social media, which offer additional forums, research has shown that these are limited in terms of audience participation, endorsements indicated by "liking", or by presenting an opportunity to dissent as activists (Koc-Michalska \& Lilleker, 2017).

The chance to shape policy is therefore limited within these additional forums and would not achieve the same level of criteria set by Innes and Booher in 1999 that the participatory processes within this research study were subjected to.

Therefore, these would not be considered meaningful, which is a critical determination in reducing inequality and according to Frederick Solt (2008). As a result of Covid-19 we have seen technology used to advance participation; however, the criteria established by Innes and Booher in 1999 remains an important evaluative tool to ensure the quality of public political participation processes to most effectively reduce inequality. 


\section{CONCLUSION}

The process and outcome analyses demonstrate greater levels of community buy-in and predictability achieved through the development of a distinctive social fabric and identity that is the foundation of high-quality place-making. Meaningful political participation opportunities are a keystone component of advanced democracies that can be optimized to further reduce inequality and strengthen communities. This exploration is worthy of further advancement and analysis to continue to maximize inclusion and economic growth while reducing inequality.

Limitations of the research include that these studies are complex and opportunities to conduct planning at this level usually only occurs every 20 or 30 years at best. Not all communities have the time and the financial means to pursue these processes at first glance. However, if studies continue to show the extrinsic and intrinsic values of these undertakings perhaps more communities will prioritize their value and see the benefit of economic growth achieved through the reduction in inequality.

Within the study it was found that property values have been increasing, as is the population in both case studies while the number of housing units were also increasing; however, it is emphasized that homeownership rates are declining. These processes have reduced inequality in terms of access and format through sophisticated collaboration. Outcomes following these processes demonstrate an increase in housing costs and a decrease in housing affordability.

Even still, political participation opportunities within these case studies are critical in that participatory equality has improved; however, methods are needed to maximize inclusion to result in even greater economic growth through a reduction in additional identified and measured forms of inequality to further advance this research.

What matters is that opportunities are sought out to continue these critical conversations and new methods are devised to ascertain a greater scope of what constitutes and perpetuates inequality since fewer opportunities for the public to participate can foster diminished levels of interest which according to Solt (2008) leads to greater levels of inequality. 


\section{AREAS FOR FURTHER RESEARCH}

These findings will be strengthened as the study is replicated throughout multiple jurisdictions that aspire to elevate public political participation and collaboration to meaningful levels that meet or surpass the criteria established by Innes and Booher (1999).

By evaluating the code formulation processes and performing before-and-after analyses on housing affordability, we can strengthen conclusions to support these processes while acknowledging the potential need for additional conversations and methods to reduce inequality that increase economic growth.

While the cases within this study represent a couple of major metropolitan areas within U.S., there is much to be learned by analyzing and comparing local contexts internationally to further consider the effects of participation and inclusion in advancing the quality of life while reducing inequality.

After visiting São Miguel Island in the Portuguese Archipelago Azores, the City of Ponta Delgada was discovered as a forerunner in terms of innovation and inclusion at the local level and is leading the way with participatory budgeting initiatives.

According to an online interview conducted with the Participatory Budget of the Azores (OP Azores), the organization "is a deliberative, direct and universal democratic process that aims to strengthen the quality of democracy, valuing participatory democracy, providing citizens with the direct decision-making power on the use of public funds, fostering the active and informed participation of citizens in the political decision-making process and stimulating economic and social cohesion, enhancing the emergence of projects that contribute to the development of the Region" (OP Azores, personal communication, November 27, 2019). While this study has centered on participation within local government planning processes, it will be enriching to consider how the quality of participation and the quality of life can be advanced through collaboration regarding budgeting goals and objectives.

Likewise, there is much to be learned in how each local context accumulates and disperses revenue and how land ownership affects the individual in terms of wealth-building and equality in local contexts throughout the world.

This will lead to advancements in the use of political participation and development to best address inequality and work to eliminate poverty. 


\section{REFERENCES}

City of Denver (2010). Chapter 59.

https://library.municode.com/co/denver/codes/code of ordinances?nodeld=TITIIREMUCO CH59ZO

City of Miami (2010). Miami 21. Miami Zoning Code. https://codehub.gridics.com/us/fl/miami

Florida Housing Finance Corporation (2016). Rental Market Study. http://www.floridahousing.org/FHImageWebDocs/Newsroom/Publications/MarketStudies/2016/2016 Full R MS fi nal.pdf

Fung, A. (2004). Empowered Participation: Reinventing Urban Democracy. Princeton University Press.

Innes, J., \& Booher, D. (1999). Consensus building and complex adaptive systems: A framework for evaluating collaborative planning [Electronic version]. Journal of the American Planning Association, 65(4), 412-423. https://doi.org/10.1080/01944369908976071

Jun, H. (2017). The Link Between Local Comprehensive Plans and Housing Affordability: A Comparative Study of the Atlanta and Detroit Metropolitan Areas. Journal of the American Planning Association, 83(3), 249-261. https://doi.org/10.1080/01944363.2017.1321496

Koc-Michalska, K., \& Lilleker, D. (2017). Digital Politics: Mobilization, Engagement, and Participation. Political Communication, 34(1), 1-5, https://doi.org/10.1080/10584609.2016.1243178

Rangwala, K. (Winter 2010). Place-based economy. Economic Development Journal, 9(1), $42-47$. https://rangwalaassoc.com/wp-content/uploads/ldeas/Articles/2010 Place based Economy.pdf

Solt, F. (2008). Economic Inequality and Democratic Political Engagement. American Journal of Political Science, 52(1), 48-60. https://doi.org/10.1111/j.1540-5907.2007.00298.x

Thomas, A. (2017). Democracy, Capital, and the Rise of the New Inequality. Political Theory, 45(6), 863-876. https://doi.org/10.1177/0090591717693754

U.S. Census Bureau (2018). Housing Vacancies and Homeownership. https://www.census.gov/housing/hvs/index.html

Watt, S., \& Wakefield, C., eds. (2017). Teaching Visual Methods in the Social Sciences. Routledge.

Wright Bowen, K. (2011). Participation and Predictability: A Comparative Analysis of Processes and Outcomes of the Form-based Codes and Previous Conventional Zoning Codes of Miami, Florida and Denver, Colorado. [Unpublished master's thesis]. University of Florida. https://ufdcimages.uflib.ufl.edu/UF/E0/04/38/62/00001/WRIGHT K.pdf 